\title{
Update on Middle Ear Barotrauma after Hyperbaric Oxygen Therapy-Insights on Pathophysiology
}

\author{
Marco Antônio Rios Lima ${ }^{1}$ Luciano Farage ${ }^{1} \quad$ Maria Cristina Lancia Cury $^{2}$ Fayez Bahamad Júnior ${ }^{1}$ \\ ${ }^{1}$ Health Science School, Universidade de Brasília, Brasilia, Distrito \\ Federal, Brazil \\ 2 Department of Hyperbaric Medicine, Armed Force Hospital, Brasilia, \\ Distrito Federal, Brazil \\ Address for correspondence Marco Antônio Rios Lima, MSc in Health \\ Science, Universidade de Brasília, Brasilia, Distrito Federal, CSB 10 \\ LOTES, 2 E 3 APTO, 1902 A Brasilia 72015605, Brazil \\ (e-mail: marcoantoniobsb@gmail.com).
}

Int Arch Otorhinolaryngol 2014;18:204-209.

\begin{abstract}
Introduction Middle ear barotrauma is the most common side effect of hyperbaric oxygen therapy. Knowledge and understanding of its pathophysiology are crucial for an accurate diagnosis and proper decision making about treatment and prevention.

Objective Describe up-to-date information on pathophysiology of middle ear barotrauma after hyperbaric oxygen therapy considering the physiology of pressure variation of the middle ear.

Data Synthesis Middle ear barotrauma occurs especially during the compression phase of hyperbaric oxygen therapy. The hyperoxic environment in hyperbaric oxygen therapy leads to ventilatory dysfunction of the eustachian tube, especially in monoplace chambers, where the patients are pressurized with $100 \% \mathrm{O}_{2}$, favoring middle ear barotrauma.

Conclusion The eustachian tube, the tympanic cavity, and mastoid work together in a neural controlled feedback system in which various mechanisms concur for middle ear pressure regulation.
\end{abstract}

\section{Introduction}

Middle ear barotrauma (MEB) occurs when individuals are unable to equalize the pressure gradient between the middle ear (ME) and the external environment. ${ }^{1}$ This can cause stretching and tearing of the structural elements of the tympanic membrane (TM). This situation can occur within minutes to hours, ${ }^{2}$ and it can happen in different environments such as hyperbaric oxygen therapy, diving, airplane flights and hypobaric chamber. Symptoms range from discomfort, ear pain, ear fullness, hearing loss, tinnitus, and even otorrhagia. ${ }^{1,3,4}$

\section{Review of Literature}

Medline, Cochrane Library, Lilacs and SciELO were searched for the terms "Middle Ear Barotrauma (MEB)" and "Hyper- baric Oxygen Therapy (HBOT)" from 1975 to 2013. We included reviews, retrospective and prospective studies, and also textbooks that addressed the MEB, especially in patients undergoing hyperbaric oxygen therapy. No systematic review or meta-analysis on this topic was found (-Table 1).

\section{Discussion}

\section{Anatomophysiology of the Middle Ear Cleft}

To understand the physiology of pressure variation of the ME cleft, it is important to review its anatomy. The ME cleft is divided by tympanic isthmus into two compartments: an anteroinferior one and another posterosuperior. The anteroinferior compartment includes the pro-, meso-, and hypotympanum and has the primary function of clearance. The received

August 27, 2013

accepted

December 2, 2013
DOI http://dx.doi.org/

10.1055/s-0034-1366974. ISSN $1809-9777$.
Copyright $(2014$ by Thieme Publicações License terms

Ltda, Rio de Janeiro, Brazil

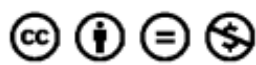


Table 1 Studies addressing MEB pathophysiology

\begin{tabular}{|c|c|c|c|c|}
\hline Studies & Year & Country & Topic & Environment \\
\hline Matos $^{38}$ & 1975 & Brazil & MEB in compression & Dive \\
\hline Ornhagen and Tallberg et al ${ }^{40}$ & 1981 & Sweden & MEB in decompression & Dive \\
\hline Carlson et $\mathrm{al}^{40}$ & 1992 & USA & MEB in decompression & HBOT \\
\hline Sadé and $\mathrm{Ar}$ et al ${ }^{40}$ & 1997 & Israel & Delayed MEB & Dive/flight \\
\hline Beuerlein et $\mathrm{al}^{40}$ & 1997 & USA & MEB in compression & HBOT \\
\hline Lacey and Amedee et al ${ }^{40}$ & 2000 & USA & MEB in compression & Dive/flight \\
\hline García et al ${ }^{40}$ & 2004 & Cuba & MEB in decompression & Dive \\
\hline Neuman and Thoom et al ${ }^{40}$ & 2008 & USA & MEB in decompression/delayed MEB & HBOT \\
\hline Landolfi et al ${ }^{40}$ & 2010 & Italy & Delayed MEB & Hypobaric chamber \\
\hline
\end{tabular}

Abbreviations: HBOT, hyperbaric oxygen therapy; MEB, middle ear barotrauma.

posterosuperior compartment includes the epi- and retrotympanum, aditus ad antrum, antrum, and mastoid air cells, with the primary function of gas exchange.

The two compartments are covered by the same respiratory mucosa. As the gas is exchanged through the mucosa of these cells, the total area of the mucosal surface directly reflects the rate of gas exchange. ${ }^{5}$

\section{Physiology of Pressure Variation of the Middle Ear}

Because the ME is a closed bony cavity covered by mucosa, relatively noncollapsible, with stable temperature, its pressure is a direct function of the volume of gas contained, changing only with the transfer of gas from ME to the systemic circulation or vice versa.

The main physiologic pathways for gas exchange between the $\mathrm{ME}$ and the external environment are the gas diffusion through the mucosa and pressure equalization by the eustachian tube (ET). The gas exchange between the ME and mixed venous blood mainly depends on the slow diffusion of nitrogen at a rate of $0.0008 \mathrm{~mm} \mathrm{Hg} / \mathrm{min}$. Although this mechanism is important in terms of steady environmental pressure, the slow pace of transmucosal gas exchange becomes irrelevant when large and rapid environmental pressure changes take place. 6

\section{Middle Ear Pressure Variation during the Day}

Studies show ME pressure variation throughout the day. 7,8 During the day, there is usually a slow and continuous decrease of pressure for a negative level slightly below atmospheric pressure. This is interrupted by rapid and intermittent pressure variations in the positive direction when the ET opens. During sleep, the course of events is reversed, like a mirror image of the pattern of the day. There is a slow and spontaneous increase of pressure to a level above atmospheric pressure, and this increase is interrupted by rapid and intermittent pressure variations in the negative direction. The gas flow is usually reversed by the ET every morning and night. In part, this may be explained by shallow breathing during sleep, which leads to increased content of carbon dioxide $\left(\mathrm{CO}_{2}\right)$ in blood and its subsequent diffusion for ME.
Diurnal variation of gas volume of the mastoid air cells may be an additional explanation. ${ }^{8}$

\section{Middle Ear Compensation Mechanisms}

The ET, the tympanic cavity and mastoid represent a complex system in which various mechanisms are associated to ensure adequate ventilation of the $\mathrm{ME}^{9}$

\section{Role of the Tympanic Membrane}

Small fluctuations in pressure gradients of the ME can be buffered by the limited mobility of TM. However, displacement of the TM can completely compensate for volume changes only by 0.2 to $0.3 \mathrm{~mL}$ and buffer negative pressures of up to $\sim 23 \mathrm{~mm} \mathrm{Hg}$ in the ME with a mean volume of $10 \mathrm{~mL}^{6}$

\section{Tympanic Membrane Retraction}

Sadé reported that the retraction of the TM is a compensatory mechanism that aims to keep the ME pressure constant. ${ }^{7}$ This balance is based on Boyle-Marriote's law, which postulates that the volume $(\mathrm{V}) \times$ pressure $(\mathrm{P})=$ constant. In case of a negative ME pressure, the reduction of the ME volume can bring back the pressure to atmospheric levels or close to them. At first the pars flaccida (PF) of TM, because of their flexibility, retracts to varying degrees in an attempt to balance the negative pressure. If there is no success in offsetting pressure, retraction of the pars tensa (PT) may occur after the destruction of its middle layer of collagen, which transforms its relatively nonrigid nature into a flexible membrane like the PF. If the negative pressure persists, other buffering mechanisms can be triggered, such as ME effusion. An effusion may fulfill and abolish a smaller or larger part of the ME volume, thereby buffering a developing negative pressure (where there is no space, no negative pressure may exist). ${ }^{7}$

The retraction of the PF reduces the volume of the ME and its pressure increases according to the volume of the entire ME cleft. As the volume of ME is relatively stable $\left(0.5 \mathrm{~cm}^{3}\right)$, the volume of the mastoid determines the degree of retraction of the TM. Then an ME cleft with a hypopneumatized mastoid with a total volume of $1 \mathrm{~cm}^{3}$ can have its volume reduced with the help of PF retraction grade 2 , at $\sim 0.5 \%$, equaling the 
equivalent of $50 \mathrm{~mm} \mathrm{H}_{2} \mathrm{O}$. The same decrease in an $\mathrm{ME}$ with a $10-\mathrm{cm}^{3}$ mastoid would have its volume reduced by $0.05 \%$, equaling the corresponding $5 \mathrm{~mm}^{3} \mathrm{H}_{2} \mathrm{O}$. There are both rapid and slow variations. Ears with normal pneumatization $\left(\sim 10 \mathrm{~cm}^{2}\right)$ would be subject to variation up to $5 \mathrm{~mm}^{3} \mathrm{H}_{2} \mathrm{O}$, and in sclerotic mastoids, pressure can decrease up to $50 \mathrm{~mm} \mathrm{H}_{2} \mathrm{O}$ (an aberration compensated by retraction of PF). ${ }^{7}$

PT retraction is more effective in cushioning the effects of the deficit of gas in the ME than the PF, due to the higher volume displaced by the PT. The potential volume displaced by PT retraction is 50 to 100 times greater than that of PF retraction. ${ }^{10}$ It seems that the grade 1 and $2 \mathrm{PF}$ retractions, as well as grade 1 through 3 PT retractions, which are reversible situations, may be physiologic expressions of damping small pressure changes because of physiologic gas fluctuations. Further retractions of PF (grades 3 and 4 ) as well as of the PT (grades 2 to 4 ) are usually not reversible because of adhesions and represent an already decompensated state and may lead to local destruction or cholesteatoma. ${ }^{10}$

Yokobori et al, ${ }^{11}$ using an ME model with different mastoid sizes, showed that the same gas deficit created a more significant retraction in artificial TM when the mastoid process did not exist, compared with the mastoid process of $60 \mathrm{~cm}^{3}$, because the negative pressure in well-pneumatized mastoids is "buffered" by the total volume of the mastoid, resulting in a pressure unable to overcome the internal rigidity of the TM.

\section{Role of the Eustachian Tube}

The ET has three physiologic functions related to the ME: equalize ME pressure with atmospheric pressure (ventilation), protect ME from nasopharyngeal sound pressure and secretions (protection), and drain secretions toward the nasopharynx (drainage). ${ }^{12}$ The first function is the one of interest for this discussion.

The balance of air pressure through the TM is maintained by the ET, which opens and allows the passage of gas. ${ }^{13}$ It acts as a one-way valve between the nasopharynx and the ME, allowing air outlet from the ME faster than the air intake of the nasopharynx. ${ }^{13,14}$

The ET is normally closed and opens through the action of the tensor veli palatini (TVP) muscle with the help of the levator veli palatini and salpingopharyngeal muscles. ${ }^{1,15}$ The diameter of the ET lumen and the function of its muscles vary among individuals, thus leading to differences in the ability to equalize pressure. ${ }^{15}$

Unlike gaseous exchange between the ME and venous blood, gas flow by the ET is fast and gradient-dependent, consists in gas exchange bolus from nasopharynx to the tympanic cavity, and is the primary mechanism for ME pressure equalization during HBOT. ${ }^{6}$

Bargues and Delonca (cited in García et al $^{16}$ ) classified the ET according to the degree of angulation and pressure equalization into three groups: group I, tubes forming an angle of 170 degrees, offset perfectly (48\% of cases); group II, tubes forming an angle of $\sim 125$ degrees, with mediocre compensation ( $30 \%$ of cases); group III, tubes forming a double S-shaped curve, with bad compensation (22\% of cases).

\section{The Role of Mastoid}

The mastoid air system constitutes the major part of the volume of the ME cleft and thus also represents the major part of the mucosal area available for gas exchange. $^{17}$

The main discussion in relation to the function of the mastoid lies in the question if it works as gas reservoir. Most authors believe that the mastoid functions as a gas reservoir, acting passively to compensate the pressure variations of the ME together with the ET. ${ }^{5,17-20}$ Others refute this idea. ${ }^{21-23}$ Several experimental models have been tested, limited by blood perfusion as well as limited by diffusion of gases, with conflicting results. $^{20,22,23}$

\section{Mastoid as a Dynamic Gas-Fluid Exchange System}

Some authors believe that the mastoid has an active and bidirectional exchange of gas and fluid, ${ }^{8,24,25}$ but without significant experimental evidence. ${ }^{22}$ More recent studies emphasize the complementary function of the mastoid in counterpressure regulation of the ME along with the ET. ${ }^{8,18}$ According to Gaihede et al, although the ET plays its role of pressure regulation particularly in rapid pressure changes, the mastoid performs a continuous regulation to lower pressure variations. ${ }^{18}$ Assuming the mucosal perfusion as directly proportional to the surface area of the mastoid, this would act as a dynamic system regulating the ME pressure by both gas and fluid exchange. According to Magnuson, the ME pressure-regulating system would be formed by three components: intermittent bidirectional gas passage by the ET, bidirectional continuous diffusion of gas through the mucosal cells, diffusion of continuous bidirectional fluid through the mucosal cells. ${ }^{8}$ Gas exchange would be somewhat passive, influenced by pressure gradients, as well as active, influenced by local and neural mechanisms. The exchange of fluids would happen by volumetric changing of the mucosa by active and passive mechanisms. ${ }^{8}$ An increase in mastoid mucosal thickness would reduce its volume of gas. Therefore gas exchange and fluid would be greater with a higher areato-volume (A/V) ratio of mastoid. The mucous fold increases its area but is not detected by computed tomography (CT). So it is reasonable to assume that the true $\mathrm{A} / \mathrm{V}$ ratio is underestimated by CT.

Ars et al verified histologically that the structure of the mastoid mucosa is almost identical to that found in the lung and nasal mucosa, which is consistent with gas exchange. Compared with other regions of the $\mathrm{ME}$, mastoid air cells are lined by highly vascularized cuboid epithelium, and the contact between the blood vessels and the basement membrane of the mucosa is closest. This indicates a prime function of gas exchange of the mastoid and confirms its importance in pressure regulation of the ME. ${ }^{26}$

Kanemaru et al recently showed that therapy with implanted regenerated mastoid air cells in patients with chronic otitis media improved gas exchange function and hence the tubal function in $70 \%$ of patients. The authors suggested a mutualistic relationship between the mastoid air system and the ET. ${ }^{27}$ 


\section{Pathophysiology of Middle Ear Barotrauma after Hyperbaric Oxygen Therapy}

\section{Tubal Dysfunction}

Tubal dysfunction is the major cause of MEB after HBOT. In general, it may be mechanical, by intraluminal blockage (ME pathology, mucosal inflammation, polyps) or extraluminal blockage (adenoid hypertrophy, nasopharyngeal cancer), or functional (failure to dilate the ET actively). Both mechanisms coexist and may lead to a relative negative pressure in the ME. Depending on their severity, the negative pressure may result in atelectasis and vasodilation of the TM. ${ }^{28}$

Patients with limited capacity for active opening of the ET, such as babies, children, sedated or comatose patients, and those under mechanical ventilation or with inflammatory processes in the nasopharynx (caused by viral infection, allergy, or gastroesophageal reflux) cannot achieve the pressure balance of the ME during increments of environmental pressure and therefore undergo MEB. Critical opening times are described for the ET: 0.1 to 0.9 seconds. ${ }^{15}$ Longer or shorter times predispose to MEB. The active opening of the ET under terrestrial conditions (normobaric), as evidenced by the movement of TM during the Valsalva maneuver, does not ensure good ventilation function of the ET during compression of the hyperbaric chamber. ${ }^{29,30}$

In monoplace chambers, patients are lying during the treatment, in the same position of patients with acute cases treated in multiplace chambers. The supine position results in increased central venous pressure and leads to venous congestion, making it more difficult to compensate the ears. The increase in blood and ME oxygen partial pressures $\left(\mathrm{PPO}_{2}\right)$, such as occurs during HBOT, causes negative pressure in the ME and transudation of fluid. ${ }^{31}$ This reflects the decrease in ventilatory function of the ET and not merely the absorption of $\mathrm{O}_{2}$ by the $\mathrm{ME} .^{32-34}$ The failure of the $\mathrm{ME}$ regulating pressure mechanism is explained by the vulnerability of ME chemoreceptor tissues to hyperoxia, similar to that described for the carotid body. This tissue is a sensory component essential for neural feedback circuits, which control ET function. ${ }^{35}$

\section{Middle Ear Barotrauma in Compression}

This is the most common form of presentation of MEB in HBOT. ${ }^{1}$ Several factors explain the high vulnerability of the ME to barotrauma under hyperbaric conditions. The rapid increase of environmental pressure during compression can overwhelm the ability of pressure regulation of the ME if active equalization is not often practiced. ${ }^{6}$

When the ambient pressure increases during the compression, the nasopharyngeal pressure elevation and mucosa surface tension keep the ET closed. The compensation of the ears then requires voluntary contraction of the TVP muscle or self-inflation maneuvers by forcing air in the ME through the ET. If these maneuvers are ineffective, a differential pressure imposed on the TM exceeding $60 \mathrm{~mm} \mathrm{Hg}$ causes pain, fullness, and possibly hearing loss. ${ }^{36}$ When the pressure of the tissue surrounding the lumen of the ET exceeds the maximum force exerted by the active contraction of the TVP muscle, blockage occurs due to compression of ET lips. ${ }^{37}$ This phe- nomenon happens when the pressure gradient reaches $\sim 90 \mathrm{~mm} \mathrm{Hg}$. At this point, the equalization can be performed only by the introduction of air into the ET by a forced Valsalva maneuver, which is associated with increased risk of barotrauma of the inner ear. Tests in hyperbaric chamber have shown that higher pressures are required for active equalization with increased rates of pressure change. The rise of ambient pressure leads to negative ME pressure and serous fluid transudation, increasing volume of tympanic cavity mucosa and reducing patency of the ET. ${ }^{6}$

Most ME barotraumas occur in the first 10 meters of compression (equivalent to 2 absolute atmospheres compression in HBOT). ${ }^{37}$ This fact is explained by Boyle's law: the closer the surface, the greater the ratio of the volume variation of a body. ${ }^{38}$

The physical manifestations of MEB are tympanic retraction, mucosal edema, rupture of small blood vessels, and serous effusion or bleeding in ME, culminating in a perforated eardrum. ${ }^{15,29}$ TM rupture occurs more often in the anterior portion over the ME orifice of the ET. It typically occurs when there is a pressure gradient between 100 and $400 \mathrm{~mm} \mathrm{Hg}{ }^{15}$

\section{Middle Ear Barotrauma in Decompression}

Under normal conditions, the exhaust air of the ME is passive and automatic, thus, the state of the mucous layer of the ET is of great importance. ${ }^{1,39}$ According to Boyle's law, the volume of the tympanic cavity increases during decompression, exerting growing force in ET, which opens passively between pressures of 23 and $38 \mathrm{~mm} \mathrm{Hg}$.

According to García et al, only when very severe variations in pressure occur ( $74 \mathrm{~mm} \mathrm{Hg} / \mathrm{s}$ ) there may be significant MEB in decompression. ${ }^{16}$ This explains the rarity of MEB during decompression (reverse barotrauma) in HBOT.

\section{Delayed Middle Ear Barotrauma}

As pressurization in a multiplace chamber is accomplished with compressed air and inhalation of $100 \%$ oxygen $\left(\mathrm{O}_{2}\right)$ is initiated only after the compression (period in which most otologic barotraumas occur), initially there would be only an influence of relative hyperoxia on (explained by Dalton's law) impairment of tubal function. However, after completion of an HBOT session, patients would be subject to ME underaeration by progressive absorption of $\mathrm{O}_{2}$ of the tympanic cavity, because this gas diffuses easily into the systemic circulation and is consumed locally before its place in the ME is filled by inhaled nitrogen $\left(\mathrm{N}_{2}\right)^{2,40}$ As tubal function would be compromised by the reflex arc of systemic hyperoxia, transient pressure equalization efforts would be ineffective after a few hours, leading to the tympanic retraction and leakage into TM and/or ME, causing delayed MEB.

In the monoplace chamber, where normally the pressurization occurs with $100 \% \mathrm{O}_{2}$, patients would theoretically be at increased risk of MEB during compression, causing greater impairment of the tube function since the beginning of treatment. $^{6}$

\section{Conclusion}

This article provides a review of the pathophysiology of MEB, particularly after HBOT. MEB occurs especially during 
the compression phase of HBOT. The ET, the tympanic cavity, and the mastoid work together in a neurally controlled feedback system in which various mechanisms concur for ME pressure regulation. Retraction of PF and PT of the TM represent a good ME compensation mechanism for negative pressures in hypopneumatized mastoids but not in well-pneumatized ones, in which the TM cannot buffer a significant amount of pressure variation. It seems that the mastoid contributes to the slow and continuous pressure equalization of the ME that occurs during the day but not to rapid variations in ME pressure, where the role of the ET appears to be decisive. The hyperoxic environment in HBOT leads to ventilatory dysfunction of the ET, especially in monoplace chambers, where the patients are pressurized with $100 \% \mathrm{O}_{2}$, favoring MEB.

\section{References}

1 Carlson S, Jones J, Brown M, Hess C. Prevention of hyperbaricassociated middle ear barotrauma. Ann Emerg Med 1992;21(12): 1468-1471

2 Sadé J, Ar A. Middle ear and auditory tube: middle ear clearance, gas exchange, and pressure regulation. Otolaryngol Head Neck Surg 1997;116(4):499-524

3 Karahatay S, Yilmaz YF, Birkent H, Ay H, Satar B. Middle ear barotrauma with hyperbaric oxygen therapy: incidence and the predictive value of the nine-step inflation/deflation test and otoscopy. Ear Nose Throat J 2008;87(12):684-688

4 Vahidova D, Sen P, Papesch M, Zein-Sanchez MP, Mueller PH. Does the slow compression technique of hyperbaric oxygen therapy decrease the incidence of middle-ear barotrauma? J Laryngol Otol 2006;120(6):446-449

5 Ars B, Dirckx J, Ars-Piret N, Buytaert J. Insights in the physiology of the human mastoid: message to the surgeon int. J Int Adv Otol 2012;8(2):296-310

6 Neuman TS, Thoom SR. Physiology and Medicine of Hyperbaric Oxygen Therapy. Philadelphia, PA: Elsevier; 2008

7 Sadé J. On the function of the pars flaccida: retraction of the pars flaccida and buffering of negative middle ear pressure. Acta Otolaryngol 1997;117(2):289-292

8 Magnuson B. Functions of the mastoid cell system: auto-regulation of temperature and gas pressure. J Laryngol Otol 2003;117(2): 99-103

9 Csakanyi Z, Katona G, Josvai E, Mohos F, Sziklai I. Volume and surface of the mastoid cell system in otitis media with effusion in children: a case-control study by three-dimensional reconstruction of computed tomographic images. Otol Neurotol 2011;32(1): 64-70

10 Sadé J. The buffering effect of middle ear negative pressure by retraction of the pars tensa. Am J Otol 2000;21(1):20-23

11 Yokobori AT Jr, Yoshinari H, Kowata I. Mechanical test methods of biomedical membranes such as used for otolaryngology. Biomed Mater Eng 1991;1(2):137-142

12 Hidir Y, Ulus S, Karahatay S, Satar B. A comparative study on efficiency of middle ear pressure equalization techniques in healthy volunteers. Auris Nasus Larynx 2011;38(4): 450-455

13 Miyazawa T, Ueda H, Yanagita N. Eustachian tube function and middle ear barotrauma associated with extremes in atmospheric pressure. Ann Otol Rhinol Laryngol 1996;105(11): 887-892

14 Kumazawa T, Iwano T, Ushiro K, Kinoshita T, Hamada E, Kaneko A. Eustachian tube function tests and their diagnostic potential in normal and diseased ears. Acta Otolaryngol Suppl 1993; 500:10-13

15 Lacey JP, Amedee RG. The otologic manifestations of barotrauma. J La State Med Soc 2000;152(3):107-111

16 García ML, Guinart DG, Castellanos RG. Barotraumatismos de Oído y otros trastornos otológicos relacionados com el buceo. Revista Virtual de Medicina Hiperbárica. January 2004. Available at: www.cccmh.com/REVISTA-OHB/Revista-OHB.htm. Accessed in Aug 8, 2013

17 Doyle WJ. The mastoid as a functional rate-limiter of middle ear pressure change. Int J Pediatr Otorhinolaryngol 2007;71(3): 393-402

18 Gaihede M, Dirckx JJJ, Jacobsen H, Aernouts J, Søvsø M, Tveterås K. Middle ear pressure regulation-complementary active actions of the mastoid and the eustachian tube. Otol Neurotol 2010;31(4): 603-611

19 Alper CM, Kitsko DJ, Swarts JD, et al. Role of the mastoid in middle ear pressure regulation. Laryngoscope 2011;121(2): 404-408

20 Cinamon U, Sadé J. Mastoid and tympanic membrane as pressure buffers: a quantitative study in a middle ear cleft model. Otol Neurotol 2003;24(6):839-842

21 Alicandri-Ciufelli M, Gioacchini FM, Marchioni D, Genovese E, Monzani D, Presutti L. Mastoid: a vestigial function in humans? Med Hypotheses 2012;78(3):364-366

22 Doyle WJ. Experimental results do not support a gas reserve function for the mastoid. Int J Pediatr Otorhinolaryngol 2000; 52(3):229-238

23 Swarts JD, Cullen Doyle BM, Alper CM, Doyle WJ. Surface areavolume relationships for the mastoid air cell system and tympanum in adult humans: implications for mastoid function. Acta Otolaryngol 2010;130(11):1230-1236

24 Koç A, Ekinci G, Bilgili AM, Akpinar IN, Yakut H, Han T. Evaluation of the mastoid air cell system by high resolution computed tomography: three-dimensional multiplanar volume rendering technique. J Laryngol Otol 2003;117(8):595-598

25 Pau HW, Sievert U, Just T, Sadé J. Pressure changes in the human middle ear without opening the eustachian tube. Acta Otolaryngol 2009;129(11):1182-1186

26 Ars B, Wuyts F, Van de Heyning P, Miled I, Bogers J, Van Marck E. Histomorphometric study of the normal middle ear mucosa. Preliminary results supporting the gas-exchange function in the postero-superior part of the middle ear cleft. Acta Otolaryngol 1997;117(5):704-707

27 Kanemaru S, Umeda H, Yamashita M, et al. Improvement of eustachian tube function by tissue-engineered regeneration of mastoid air cells. Laryngoscope 2013;123(2):472-476

28 Flint PW, Haughey BH, Lund VJ, et al. Cummings Otolaryngology Head and Neck Surgery. 5th ed. Philadelphia, PA: Elsevier; 2010

29 Beuerlein M, Nelson RN, Welling DB. Inner and middle ear hyperbaric oxygen-induced barotrauma. Laryngoscope 1997; 107(10):1350-1356

30 Shupak A, Sharoni Z, Ostfeld E, Doweck I. Pressure chamber tympanometry in diving candidates. Ann Otol Rhinol Laryngol 1991;100(8):658-660

31 Shupak A, Attias J, Aviv J, Melamed Y. Oxygen diving-induced middle ear under-aeration. Acta Otolaryngol 1995;115(3): 422-426

32 Shupak A, Tabari R, Swarts JD, Bluestone CD, Doyle WJ. Effects of middle ear oxygen and carbon dioxide tensions on eustachian tube ventilatory function. Laryngoscope 1996;106(2 Pt 1): 221-224

33 Shupak A, Tabari R, Swarts JD, Bluestone CD, Doyle WJ. Effects of systemic hyperoxia on eustachian tube ventilatory function. Laryngoscope 1997;107(10):1409-1413

34 Buckingham RA, Stuart DR, Geick MR, Girgis SJ, McGee TJ. Experimental evidence against middle ear oxygen absorption. Laryngoscope 1985;95(4):437-442 
35 Eden AR, Gannon PJ. Neural control of middle ear aeration. Arch Otolaryngol Head Neck Surg 1987;113(2):133-137

36 Blanshard J, Toma A, Bryson P, Williamson P. Middle ear barotrauma in patients undergoing hyperbaric oxygen therapy. Clin Otolaryngol Allied Sci 1996;21(5):400-403

37 Uzun C, Adali MK, Tas A, Koten M, Karasalihoglu AR, Devren M. Use of the nine-step inflation/deflation test as a predictor of middle ear barotrauma in sports scuba divers. Br J Audiol 2000;34(3):153-163
38 Matos A. Middle Ear Barotrauma in Divers [doctoral thesis]. Rio de Janeiro, Brazil: Brazilian Academy of Military Medicine; 1975

39 Ornhagen HC, Tallberg P. Pressure equilibration of the middle ear during ascent. Undersea Biomed Res 1981;8(4):219-227

40 Landolfi A, Autore A, Torchia F, Ciniglio Appiani M, Morgagni F, Ciniglio Appiani G. Ear pain after breathing oxygen at altitude: prevalence and prevention of delayed barotrauma. Aviat Space Environ Med 2010;81(2):130-132 